\title{
Persistência do baculovírus anticarsia após diferentes regimes pluviométricos
}

\author{
Velvet-bean nucleopolyhedrovirus persistence after different rainfall intensities
}

\author{
Valter Pessoa ${ }^{\mathrm{I}}$ Fabiane Cunha ${ }^{\mathrm{I}}$ Adeney de Freitas Bueno ${ }^{\mathrm{I}}{ }^{*}$ Orcial Ceolin Bortolotto ${ }^{\mathrm{II}, \mathrm{III}}$ \\ Talita Monteiro ${ }^{\mathrm{IV}}$ Vânia Maria Ramos ${ }^{\mathrm{I}}$
}

\section{RESUMO}

\begin{abstract}
A persistência do vírus da lagarta-da-soja AgMNPV, produzido de forma bruta (maceração de lagartas) e liofilizada (produto comercial), foi avaliada após a aplicação em plantas de soja seguida de diferentes regimes pluviométricos $(0 ; 10 ; 20$; $30 \mathrm{~mm}$ ) na intensidade de $30 \mathrm{~mm}$. hora $^{-1}$. Essas precipitações foram simuladas com microaspersores, em casa-de-vegetação. Após a simulação, a soja foi oferecida às lagartas zero, três, seis e nove dias após a aplicação (DAP). As plantas, durante esse período, foram mantidas em casa-de-vegetação, protegidas da chuva. $O$ experimento foi conduzido em delineamento inteiramente casualizado em condições controladas (UR $70 \pm 10 \%, 25 \pm 2^{\circ} \mathrm{C}$, fotofase de 14h), em esquema fatorial 4 (intensidades de precipitações pluviométricas) $\times 2$ (formulações de vírus, bruta e liofilizada) com quatro repetições, com 30 lagartas cada. Os resultados comprovam que precipitações até $30 \mathrm{~mm}$, em 60 minutos, não reduzem a mortalidade das lagartas, causada por AgMNPV em ambas as formas de produção, quando a oferta das folhas às lagartas ocorre no mesmo dia da aplicação. As formas de preparo do AgMNPV influenciaram na persistência do vírus aos seis DAP. Nesta avaliação, a taxa de mortalidade foi superior a $90 \%$, quando o produto bruto foi aplicado e inferior a $50 \%$ para o produto liofilizado. Esses resultados indicam que a eficiência de AgMNPV não é afetada por chuvas de até $30 \mathrm{~mm}$ em uma hora, para ambas as formas de preparo do AgMNPV. Entretanto, ao longo dos dias, o método de preparo bruto apresenta-se mais eficiente, devido à maior persistência sobre a área foliar da soja após a lavagem pela água.
\end{abstract}

Palavras-chave: baculovírus, fatores abióticos, Glycine max, Anticarsia gemmatalis, entomopatógeno.

\section{ABSTRACT}

The persistence of the velvet-bean
nucleopolyhedrovirus (AgMNPV) produced raw (macerated caterpillars) and lyophilized (commercial product) was evaluated after spraying in soybean plants followed by different simulated rainfall rates $(0 ; 10 ; 20 ; 30 \mathrm{~mm})$ at $30 \mathrm{~mm}^{\text {hour }}{ }^{-1}$ rate. Rainfall was simulated in greenhouse through micro sprinkler irrigation. After simulated rainfall, soybean leaves were offered to caterpillar in laboratory conditions at zero, three, six and nine days after spraying (DAS). Soybean plants were kept in greenhouse protected from rainfall. Trial was carried out in complete randomized design, under controlled conditions (RH $70 \% \pm 10 \%, 25 \pm 2^{\circ} \mathrm{C}, 14 \mathrm{~h}$ photophase) in a factorial 4 (rainfall rates) x2 (formulations, raw and lyophilized) with four replicates of 30 caterpillars. Results indicate that rainfall rates up to $30 \mathrm{~mm}$, in 60 minutes, do not decrease caterpillar mortality caused by AgMNPV regarding to both tested baculovirus formulations, raw and lyophilized virus, when leaves were offered to caterpillars at zero DAS. However, virus production (raw or lyophilized) impacted its persistence. Six DAS, mortality rate was higher than $90 \%$ when the virus was applied raw and lower than $50 \%$ when it was applied lyophilized. These results suggest that both raw and lyophilized AgMNPV efficacy is not impaired by $30-\mathrm{mm}$ rainfalls at $30 \mathrm{~mm}^{\text {hour }}{ }^{-1}$ rate. However, raw virus was more efficient in a long term evaluation since it had longer persistence on soybean leaves after being water washed.

Key words: baculovirus, abiotic factors, Glycine max, Anticarsia gemmatalis, entomopathogen.

\section{INTRODUÇÃO}

O programa de controle biológico aplicado, utilizando-se o AgMNPV, foi caracterizado por além de sua eficiência no controle da lagarta-da-soja, principalmente pela facilidade de aplicação do vírus pelo sojicultor. De forma geral, o produtor realizava

IUniversidade do Oeste Paulista (UNOESTE), Presidente Prudente, SP, Brasil.

IEmbrapa Soja, CP 231, 86001-970, Londrina, PR, Brasil. E-mail: adeney.bueno@embrapa.br. *Autor para correspondência.

IIIDepartamento de Zoologia, Universidade Federal do Paraná (UFPR), Curitiba, PR, Brasil.

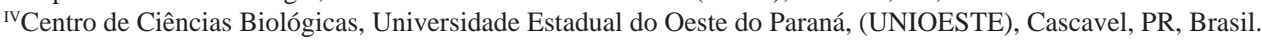
Recebido 11.03.13 Aprovado 10.08.13 Devolvido pelo autor 07.11.13 CR-2013-0323.R1 
a coleta de algumas lagartas infectadas pelo vírus e, após macerá-las em água, realizava a pulverização da suspensão (produto bruto), ou em alguns casos, utilizavam o pó liofilizado (formulações comerciais) (MOSCARDI, 1999). Apesar do sucesso inicial desse programa, nos últimos anos, a área onde esse vírus é aplicado vem sendo reduzida gradativamente. Isso pode ser considerado um grande erro por parte dos sojicultores, porque o AgMNPV, para o controle da Anticarsia gemmatalis Hübner, 1818 (Lepidoptera: Erebidae), constitui-se em um componente fundamental para ser incorporado em programas de manejo integrado de pragas da soja (MIP-Soja), visando à redução da aplicação de agrotóxicos com maior impacto ambiental e não seletivos aos inimigos naturais. Entretanto, é importante salientar que esses entomopatógenos têm ação lenta (aproximadamente sete a oito dias) e podem ser muito sensíveis aos fatores ambientais, como a radiação da luz solar e precipitação pluviométrica, que podem afetar significativamente a persistência desses inseticidas microbianos (IGNOFFO, 1992).

Apesar da importância dos fatores ambientais sobre a eficiência das aplicações dos entomopatógenos, os efeitos da precipitação pluviométrica sobre a ação dos baculovírus ainda é desconhecida. Surpreendentemente, poucas pesquisas têm sido realizadas nessa área. Entre essas pesquisas, estão os trabalhos de IGNOFFO et al. (1997), que estudaram o efeito da precipitação pluviométrica sobre ação do baculovírus heliothis na cultura da soja, utilizando chuva artificial de $12,5 \mathrm{~mm}$ em 30 segundos, e concluíram que menos de $6 \%$ da atividade do baculovírus foi prejudicada com a simulação da precipitação pluviométrica. Semelhantemente, o granulovírus de Pieris brassicae (Linnaeus, 1758) (Lepidoptera: Pieridae), na sua formulação bruta ou parcialmente purificada, aplicado em folhas de repolho, não foi significativamente removido pela exposição por cinco horas de chuva simulada, ou por lavagem com detergente (DAVID \& GARDINER, 1966). No entanto, YOUNG (1990) relatou que vírus (corpos de inclusão) de cadáveres de Chrysodeixis includens (Walker, [1858]) (Lepidoptera: Noctuidae) foram lavados das folhas de soja após elas serem submetidas a 62,5mm de irrigação por aspersão, mostrando a importância de se testar diferentes situações para cada espécie de vírus. Nesse contexto, há muito pouca informação sobre o AgMNPV. Devido à escassez de informações nesta área, são importantes estudos que avaliem a capacidade de diferentes intensidades pluviométricas de reduzirem a eficiência desses patógenos no controle da A. gemmatalis.
Portanto, este trabalho objetivou avaliar o impacto da chuva simulada sobre a eficácia de AgMNPV ao longo do tempo.

\section{MATERIAL E MÉTODOS}

Semeadura e tratos culturais da soja

A cultivar de soja utilizada foi a BRS 284 semeada em 36 vasos de plástico (volume $=3,0 \mathrm{~L}$ ), medindo $21,0 \mathrm{~cm}$ de diâmetro e $17,0 \mathrm{~cm}$ de altura. A adubação da cultura ocorreu de acordo com o resultado da análise de solo, seguindo as recomendações para a cultura (RAIJ et al., 1999). Posteriormente, esses vasos foram acondicionados em casa-de-vegetação, onde a irrigação por gotejamento foi realizada de forma contínua, para manter a umidade do solo próximo à capacidade de campo. $\mathrm{O}$ desbaste foi realizado no estádio $\mathrm{V}_{1}$ da cultura (escala fenológica de FEHR et al., 1971), que foi aos oito dias após a emergência das plantas, mantendo-se quatro plantas/vaso.

\section{Criação da lagarta-da-soja}

As lagartas utilizadas nos experimentos foram provenientes da criação de insetos do laboratório da Embrapa Soja. Esses insetos são criados por sucessivas gerações, em condições controladas de temperatura $\left(25 \pm 2^{\circ} \mathrm{C}\right)$, umidade relativa $(60 \pm 10 \%)$ e fotofase de 14 horas em dieta artificial, conforme GREENE (1976) e HOFFMANN-CAMPO (1985).

Modos de preparação do vírus

Para AgMNPV liofilizado, foi utilizado um produto comercial com a composição de 73,0\% de caulinita e 26,4\% de matéria orgânica. A concentração do AgMNPV foi de 7,0×109 corpos de poliedros de inclusão (cpi grama-1 de produto).

O AgMNPV bruto foi obtido com o esmagamento de lagartas de A. gemmatalis contaminadas com vírus. Lagartas de terceiro instar foram alimentadas com dieta artificial contendo AgMNPV. Sete dias após o início da alimentação, as lagartas morreram, devido à infecção provocada pelo vírus. Imediatamente após a morte, as lagartas foram maceradas e, posteriormente, coadas e centrifugadas a 10000rpm por 15 minutos, obtendo-se uma suspensão na concentração de $3,0 \times 10^{9} \mathrm{cpi} \mathrm{mL}^{-1}$ de solução.

\section{Concentração de baculovírus utilizada}

Para os bioensaios, padronizou-se a concentração de $1,5 \times 10^{11} \mathrm{cpi} \mathrm{ha}^{-1}$, a qual é a concentração recomendada para o AgMNPV (TECNOLOGIAS, 2010). Como as concentrações dos vírus foram de $7,0 \times 10^{9}$ para o liofilizado e $3,0 \times 10^{9}$ para 
o bruto, padronizaram-se as doses de 0,19 e $0,44 \mathrm{~mL}$ $\mathrm{L}^{-1}$ de água para o AgMNPV bruto e liofilizado, respectivamente. $\mathrm{O}$ volume de calda utilizado foi de um litro, aplicado em uma área de $66,0 \mathrm{~m}^{2}$, o que corresponde a 151,5L de volume de calda ha $^{-1}$.

Aplicação do baculovírus: AgMNPV foi aplicado sobre as plantas de soja no estádio $\mathrm{V}_{5}$ (FEHR et al., 1971), com auxílio de um pulverizador costal propulsionado a ar comprimido $\left(\mathrm{CO}_{2}\right)$, com vazão 151,5L de volume de calda ha ${ }^{-1}$ e pressão de 50,0 libras pol $^{-2}$, adaptado com uma barra composta por quatro bicos tipo cone JD 14-1, espaçados 0,5m.

Simulações de chuva: a simulação da precipitação pluviométrica foi realizada em casade-vegetação, por meio de sistema de irrigação por aspersão. Os volumes de chuva utilizados foram de $0,10,20$ e 30mm, em uma intensidade de chuva de 30mm.hora ${ }^{-1}$.

Condução do experimento: o experimento foi conduzido em delineamento inteiramente casualizado, em esquema fatorial 4 (intensidades de precipitação pluviométrica; $0 \mathrm{~mm}, 10 \mathrm{~mm}, 20 \mathrm{~mm}$ e 30mm)x2 (preparos do vírus; bruto e liofilizado), com quatro repetições, compostas de 30 lagartas cada, totalizando 32 unidades experimentais (vasos).

Após a aplicação do AgMNPV sobre a área foliar da soja, aguardou-se 30 minutos para as plantas secarem, sendo que posteriormente foram submetidas às precipitações pluviométricas. Em sequência à chuva artificial, aguardaram-se novamente 30 minutos, para a evaporação da água superficial das folhas. Após isso, foram retirados dois trifólios do terço superior das plantas e fornecidas para as 30 lagartas de $\boldsymbol{A}$. gemmatalis de $3^{\text {o }}$ ínstar de cada repetição, acondicionadas em caixas de acrílico tipo gerbox.

As lagartas se alimentaram das folhas de soja por um período de 48 horas, em condições controladas de laboratório (UR $70 \pm 10 \%, 25 \pm 2^{\circ} \mathrm{C}$ e fotofase de 14 horas). Após esse período, os espécimes foram transferidos para copos plásticos (volume de $50,0 \mathrm{~mL}$ ), onde se ofertou dieta artificial para a praga (GREENE, 1976; HOFFMANN-CAMPO, 1985), trocada, no mínimo, duas vezes/semana. Dentro de cada copo, foram colocadas três lagartas, totalizando 10 copos repetição-1. As avaliações ocorreram diariamente até a morte da praga ou emergência do adulto. A oferta de folhas pulverizadas com o vírus às lagartas ocorreram aos três, seis e nove dias após a aplicação do vírus, visando avaliar o efeito residual do AgMNPV.

Os resultados obtidos foram submetidos às análises exploratórias para avaliar as pressuposições de normalidade dos resíduos, homogeneidade de variância dos tratamentos e aditividade do modelo para permitir a aplicação da ANOVA (BURR \& FOSTER, 1972; SHAPIRO \& WILKS, 1965). Quando necessário, os dados foram transformados em $\sqrt{X}$. As médias foram comparadas pelo teste de Tukey a $5 \%$ de probabilidade de erro (SAS INSTITUTE, 2001).

\section{RESULTADOS E DISCUSSÃO}

Na avaliação realizada no mesmo dia da aplicação do AgMNPV, a chuva simulada de 10, 20 ou 30mm não afetou a eficiência do entomopatógeno ( $\mathrm{P}=0,8297)$, que causou mortalidade da praga acima de 90\% em todos os tratamentos, independente do modo de preparo do produto (vírus bruto ou liofilizado) (Tabela 1). Resultados similares foram reportados por TUAN et al. (1989), em que mesmo uma intensidade de chuva superior à utilizada em nosso estudo (242mm em 30 minutos) não foi suficiente para reduzir a eficiência do baculovirus heliothis, que mantevese sempre acima de 90\%. Entretanto, essa boa persistência do baculovirus à lavagem pela chuva não pode ser generalizada para todas as condições, visto que resultados diferentes ao reportado neste trabalho também são encontrados na literatura. Por exemplo, a mortalidade de Malacosoma neustria (Linnaeus, 1758) (Lepidoptera: Lasiocampidae) por NPVMn pode ser reduzida em até $50 \%$ após uma chuva de 20mm em 10 minutos e chegar a uma eficiência de apenas $10 \%$ após uma chuva de intensidade de 300mm em 30 minutos (JANKEVICA et al., 1998). As razões para esses resultados divergentes são ainda desconhecidas e precisam ser mais bem estudados em trabalhos futuros, porém, dentre algumas hipóteses que podem explicar essas diferenças, estão o pH da água, horário de aplicação do produto, volume de calda utilizado que precisam ser avaliados (SILVA \& MOSCARDI, 2002), além das diferenças específicas de cada vírus ou hospedeiro avaliado. Adicionalmente, também se deve considerar o tamanho da gota e da energia cinética da chuva, além da estrutura do dossel das culturas estudadas (AYLOR, 1990; MADDEM, 1997; ERPUL et al., 2004; LEGUÉDOIS et al., 2005).

Embora a chuva de até $30 \mathrm{~mm}$ em 60 minutos não tenha causado impacto sobre a eficiência de AgMNPV, neste estudo, quando se avaliou a mortalidade da praga alimentada com as folhas em diferentes dias após a pulverização (DAP) do baculovirus, foi registrado que, para o vírus bruto assim como o liofillizado, esse entomopatógeno foi negativamente impactado pela chuva ao longo do tempo. Comparando o AgMNPV bruto e liofilizado, 
foi observado que o produto preparado na forma bruta apresentou maior resistência à chuva do que o liofilizado (Tabela 1). A diferença na eficiência entre as duas forma de preparo foi mais evidente aos 6 DAP ( $\mathrm{P}<0,0001$ ), quando o baculovírus preparado na forma bruta apresentou mortalidade acima de $90 \%$, mesmo quando submetido ao maior volume de precipitação (30mm), enquanto o modo de preparo liofilizado teve 75\% de sobrevivência na testemunha (sem chuva) e menos que $50 \%$ de eficiência quando submetido aos diferentes volumes de chuva (Tabela 1).

Essa diferença na taxa de mortalidade da praga sugere que existe uma maior persistência foliar do produto bruto sobre a folha de soja. Resultados similares foram anteriormente relatados por SILVA \& MOSCARDI (2002), em que foi observado um desempenho superior da formulação bruta, quando comparado com formulações liofilizadas. Dentre as possíveis razões para essa diferença, existem duas que merecem destaque: 1) as características físicas da hemolinfa da lagarta, presentes na forma bruta, que apresentam um aspecto de pegajosidade, e podem funcionar como uma cola, aumentando a aderência do vírus sobre a superfície foliar; e 2) as características dos compostos químicos da hemolinfa, que podem proporcionar maior proteção aos raios UV (CHERRY et al., 2000), que é o fator climático que exerce maior influência sobre a atuação do baculovírus (SHAPIRO et al., 2002).

O impacto da chuva sobre a redução na eficiência de baculovírus ao longo do tempo já foi relatada por outros autores para outras espécies de pragas e vírus. Por exemplo, uma semana após a simulação de chuva (50mm em 50 minutos) sobre a aplicação de Anagrapha falcifera MNPV (forma bruta) para o controle de Trichoplusia ni (Hübner, 1800-1803) (Lepidptera: Noctuidae), a mortalidade da praga foi de apenas $10 \%$ da população (TAMEZ-

Tabela 1 - Número médio de lagartas mortas \pm EP (mortalidade \%) de Anticarsia gemmatalis por baculovírus anticarsia (AgMNPV) ao longo do tempo sob diferentes níveis de precipitações pluviométricas $(\mathrm{n}=32)$.

\begin{tabular}{|c|c|c|c|}
\hline \multirow{2}{*}{ Precipitação (mm) } & \multirow[b]{2}{*}{ Bruto } & repardça do & \multirow[b]{2}{*}{ Média } \\
\hline & & Liofilizado & \\
\hline & \multicolumn{3}{|c|}{ 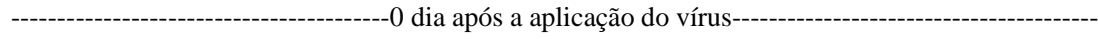 } \\
\hline 0 & $29,5 \pm 0,3$ aA $(98,3 \%)$ & $26,8 \pm 0,8$ aA $(89,2 \%)$ & - \\
\hline 10 & $29,8 \pm 0,3$ aA $(99,2 \%)$ & $25,0 \pm 1,8 \mathrm{aB}(83,3 \%)$ & - \\
\hline 20 & $27,3 \pm 1,1$ aA $(90,2 \%)$ & $27,5 \pm 0,3$ aA $(91,7 \%)$ & - \\
\hline 30 & $27,3 \pm 1,3$ aA $(90,8 \%)$ & $27,5 \pm 0,8$ aA $(91,7 \%)$ & - \\
\hline \multirow[t]{2}{*}{ CV $(\%)$} & 7,10 & & \\
\hline & 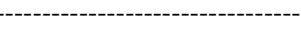 & após a aplicação do vírus- & 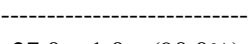 \\
\hline 0 & $28,8 \pm 0,5$ & $25,3 \pm 1,6$ & $27,0 \pm 1,0$ a $(90,0 \%)$ \\
\hline 10 & $29,0 \pm 0,4$ & $24,8 \pm 1,7$ & $26,9 \pm 1,1$ a $(89,6 \%)$ \\
\hline 20 & $28,8 \pm 0,6$ & $22,5 \pm 1,0$ & $25,6 \pm 1,3$ a $(85,4 \%)$ \\
\hline 30 & $27,8 \pm 0,3$ & $23,0 \pm 1,2$ & $25,4 \pm 1,1$ a $(84,6 \%)$ \\
\hline Média & $28,6 \pm 0,2$ A $(95,2 \%)$ & $23,9 \pm 0,7$ B $(79,6 \%)$ & - \\
\hline \multirow[t]{2}{*}{ CV (\%) } & 7,96 & & \\
\hline & 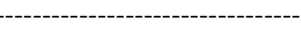 & após a aplicação do vírus- & -1-----' \\
\hline 0 & $28,00 \pm 0,41$ aA $(93,3 \%)$ & $22,50 \pm 1,32 \mathrm{aB}(75,0 \%)$ & - \\
\hline 10 & $27,50 \pm 0,65$ aA $(91,7 \%)$ & $14,00 \pm 0,41 \mathrm{bB}(46,7 \%)$ & - \\
\hline 20 & $28,50 \pm 0,65$ aA $(95,0 \%)$ & $12,00 \pm 0,81$ bB $(40,0 \%)$ & - \\
\hline 30 & $27,25 \pm 0,75$ aA $(90,8 \%)$ & $13,00 \pm 1,29$ bB $(43,3 \%)$ & - \\
\hline \multirow[t]{2}{*}{ CV (\%) } & 7,89 & & \\
\hline & 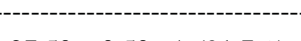 & após a aplicação do vírus- & ------ \\
\hline 0 & $27,50 \pm 0,50$ aA $(91,7 \%)$ & $14,25 \pm 1,11 \mathrm{aB}(47,5 \%)$ & - \\
\hline 10 & $20,75 \pm 0,48$ bA $(69,2 \%)$ & $12,75 \pm 2,05 \mathrm{aB}(42,5 \%)$ & - \\
\hline 20 & $16,75 \pm 1,93$ bA $(55,8 \%)$ & $11,50 \pm 0,65 \mathrm{aB}(38,3 \%)$ & - \\
\hline 30 & $21,75 \pm 1,75$ bA $(72,5 \%)$ & $10,25 \pm 0,63 \mathrm{aB}(34,2 \%)$ & - \\
\hline CV (\%) & 15,36 & & \\
\hline
\end{tabular}

Médias seguidas de mesma letra minúscula nas colunas e maiúsculas nas linhas em cada dia após a aplicação do vírus, não diferem pelo teste de Tukey em nível de 5\% de probabilidade.

Ciência Rural, v.44, n.1, jan, 2014. 
GUERRA, 2000), o que foi corroborado pelos resultados obtidos por DUAN et al. (2012). Essa redução da mortalidade da praga, provavelmente, está associada com o menor número de poliedros do vírus que permanecem sobre a área foliar após a chuva. Isso também foi evidenciado por PRATER (2002), que demonstraram que as doses subletais do vírus permitem que o inseto desenvolva-se normalmente, de modo que tenha pouca ou nenhuma influência sobre os aspectos biológicos da praga. Desse modo, é esperado que, com o passar do tempo, o baculovírus, mesmo na forma bruta, perca a eficiência de controle da praga, justificando os resultados obtidos em nosso estudo (Tabela 1), que é o primeiro relatado da persistência comparada de AgMNPV na forma bruta e liofilizada, após diferentes intensidades de chuva simuladas.

Neste estudo, foi possível observar que, de forma geral, o AgMNPV (bruto e liofilizado) apresenta boa persistência à chuva, entretanto, os resultados indicam claramente que o produto bruto é ainda mais persistente ao longo do tempo após as precipitações pluviométricas avaliadas (Tabela 1). Sendo assim, aplicações do baculovírus bruto, ou seja, a partir das próprias lagartas infectadas, são as mais apropriadas para obter melhores resultados no controle da lagarta-da-soja.

\section{CONCLUSÃO}

A precipitação pluviométrica de até 30mm, em 60 minutos, não interfere na eficiência do AgMNPV, para lagartas que se alimentarem no mesmo dia da aplicação, porém o efeito residual é reduzido ao longo do tempo, principalmente para o vírus liofilizado.

\section{REFERÊNCIAS}

AYLOR, D.E. The role of intermittent wind in the dispersal of fungal pathogens. Annual Review of Phytopatology, v.28, p.73-92, 1990. Disponível em: <http://www.annualreviews. org/doi/pdf/10.1146/annurev.py.28.090190.000445.> doi: 10.1146/annurev.py.28.090190.000445. Acesso em: 22 fev. 2013.

BURR, I.W.; FOSTER, L.A. A test for equality of variances. West Lafayette: University of Purdue, 1972. 26p.

DAVID, W.A.L.; GARDINER, B.O.C. Persistence of a granulosis virus of Pieris brassicae on cabbage leaves. Journal of Invertebrate Pathology, v.8, p.180-183, 1966. Disponível em: <http://www.sciencedirect.com/science/article/ pii/0022201166901273>. Acesso em: 24 fev. 2013.

CHERRY, A.J. et al. Field evaluation of Helicoverpa armigera nucleopolyhedrovirus formulations for control of the chickpea pod-borer, H. armigera (Hubn.), on chickpea (Cicer arietinum var. Shoba) in southern India. Crop Protection, v.19, p.51-60, 2000. Disponível em: <http://www.sciencedirect.com/science/ article/pii/S0261219499000897>. Acesso em: 01 jan. 2013. doi: 10.1016/S0261-2194(99)00089-7.

DUAN et al. Field testing chinese and Japanese gypsy moth nucleopolyhedrovirus and Disparvirus against a chinese population of Lymantria Dispar Asiatica in Huhhot, Inner Mongolia, People's Republic of China. Journal of Economic Entomology, v.105, p.344353, 2012. Disponível em: <http://www.bioone.org/doi/pdf/10.1603/ EC11294>. Acesso em: 22 fev. 2013. doi: 10.1603/EC11294.

ERPUL, G. et al. Splash-saltation trajectories of soil particles under wind-driven rain. Geomorphology, v.59, p.31-42, 2004. Disponível em: <http://dx.doi.org/10.1016/j. geomorph.2003.09.003>. Acesso em: 11 fev. 2013.

FEHR, W.R. et al. Stage of development description for soybeans, Glycine max (L.) Merril. Crop Science, v.11, p.929-930, 1971. Disponível em: <https://www.crops.org/publications/cs/ pdfs/11/6/CS0110060929>. Acesso em: 09 out. 2012.

GREENE, G.L. et al. Velvetbean caterpillar: a rearing procedure and artificial medium. Journal of Economic Entomology, v.69, p.487-488, 1976. Disponível em: <http://www.ingentaconnect. com/content/esa/jee/1976/00000069/00000004/art00020>. Acesso em: 24 set. 2012.

HOFFMANN-CAMPO, C.B. et al. Criação massal da lagarta-da-soja (Anticarsia gemmatalis). Londrina: Setor de Entomologia Agrícola, 1985. 20p. (EMBRAPA-CNPSo. Documentos, 10).

IGNOFFO, C.M. Environmental factors affecting persistence of entomopathogens. Florida Entomologist, v.75, p.516-525, 1992. Disponível em: <http://www.jstor.org/discover/10.2307/ 3496133 ? uid $=363288471$ \&uid $=3737664$ \&uid $=2129$ \&uid $=590$ 9624\&uid=2\&uid=70\&uid=3\&uid=67\&uid $=62 \&$ uid $=23539 \&$ s id=21101929829207>. Acesso em: 30 ago. 2012.

IGNOFFO, C.M. et al. Sunlight stability and rain-fastness of formulations of baculovirus heliothis. Environmental Entomology, v.26, p.1470-1474, 1997. Disponível em:<http://www. ingentaconnect.com/content/esa/envent/1997/00000026/00000006/ art00037>. Acesso em: 30 ago. 2012.

JANKEVICA, L. et al. Biological control of the European tent caterpillar Malacosoma Neustria L. (Lepidoptera, Lasiocampidae) population with different virus formulations. Latvijas Entomologs, v.36, p.11-16, 1998. Disponível em: <http://leb.daba.lv/36-j1.pdf>. Acesso em: 19 ago. 2012.

LEGUÉDOIS, S. et al. Splash projection distance for aggregated soils. Theory and experiment. Soil Science Society of American Journal, v.69, p.30-37, 2005. Disponível em: <http://www. citeulike.org/user/peterheng/article/5708980>. doi:10.2136/ sssaj2005.0030. Acesso em: 11 fev. 2013.

MADDEM, L.V. Effects of rain on splash dispersal of fungal pathogens. Canadian Journal of Plant Pathology, v.69, p.3037, 1997. Disponível em: <http://www.tandfonline.com/doi/abs/ 10.1080/07060669709500557?journalCode=tcjp20\#preview doi: 10.1080/07060669709500557>. Acesso em: 22 fev. 2013.

MOSCARDI, F. Assessment of the application of baculoviruses for control of Lepidoptera. Annual Review of Entomology, v.44, 
p.257-289, 1999. Disponível em: <http://www.annualreviews.org/ doi/full/10.1146/annurev.ento.44.1.257>. Acesso em: 23 out. 2012.

PRATER, C.A. Microbial control of Black cutworm (Lepidoptera: Noctuidae) in turfgrass using Agrotis ipsilon multiple nucleopolyhedrovirus. Journal of Economic Entomology, v.99, p.1129-1137, 2002. Disponível em: <http:// www.ncbi.nlm.nih.gov/pubmed/16937664> doi: <http://dx.doi. org/10.1603/0022-0493-99.4.1129>. Acesso em: 19 out. 2012.

RAIJ, B. van. et al. Recomendação de adubação e calagem para o estado de São Paulo. Campinas: Instituto Agronômico e Fundação IAC, 1999. 285p.

SAS INSTITUTE. SAS user's guide: statistics, version 8e. Cary, NC, 2001. 235p.

SHAPIRO, S.S; WILK, M.B. An analysys of variance test for normality (complete samples). Biometrika, v.52, p.591-611, 1965. Disponível em: <http://sci2s.ugr.es/keel/pdf/algorithm/ articulo/shapiro1965.pdf>. Acesso em: 11 ago. 2012.

SHAPIRO, M. et al. Effects of virus concentration and ultraviolet irradiation on the activity of corn earworm and beet armyworm (Lepidoptera: Noctuidae) nucleopolyhedrosis. Journal of Economic Entomology, v.95, n.2, p.243-249, 2002. Disponível em: <http://naldc.nal.usda.gov/download/11405/PDF>. Acesso em: 23 set. 2012.
SILVA, M.T.B.; MOSCARDI, F. Field efficacy of the nucleopolyhedrovirus of Anticarsia gemmatalis Hubner (Lepidoptera: Noctuidae): Effect of formulations, whater $\mathrm{pH}$, volume and time of application, and type of nozzle. Neotropical Entomology, v.31, n.1, p.75-83, 2002. Disponível em: <http:// www.scielo.br/pdf/ne/v31n1/11182.pdf>. Acesso em: 22 ago. 2012.

TAMEZ-GUERRA, P. et al. Sunlinght persistence and rainfastness of sprayed-dried formulations of baculovirus isolated from Anagrapha falcifera (Lepidoptera: Noctuidae). Journal of Economic Entomology, v.93, n.3, p.210-218, 2000. Disponível em: <http:// naldc.nal.usda.gov/download/24800/PDF>. Acesso em: 16 set. 2012.

TECNOLOGIAS DE PRODUÇÃO DE SOJA - região central do Brasil 2011. Londrina: Embrapa Soja; Embrapa Cerrados; Embrapa Agropecuária Oeste, 2010. 225p. (Sistemas de Produção, 14). 255p.

TUAN, S.J. et al. Factors affecting pathogenicity of NPV preparations to the corn earworm, Heliothis armigera. Entomophaga, v.34, p.541-559, 1989. Disponível em: <http://www.springerlink.com/ content/h415802040g6h337/>. Acesso em: 11 set. 2012.

YOUNG, S.Y. Influence of sprinkler irrigation on dispersal of nuclear polyhedrosis virus from host cadavers on soybean. Environmental Entomology, v.19, p.717-720, 1990. Disponível em: <http://www.ingentaconnect.com/content/esa/ envent/1990/00000019/00000003/art00044?crawler=true $>$. Acesso em: 13 out. 2012. 